\title{
Update on Outcome Measure Development in Large-vessel Vasculitis: Report from OMERACT 2018
}

\author{
Sibel Z. Aydin, Joanna C. Robson, Antoine G. Sreih, Catherine Hill, Fatma Alibaz-Oner, \\ Sarah Mackie, Susan Beard, Ahmet Gul, Gülen Hatemi, Tanaz A. Kermani, Alfred Mahr, \\ Alexa Meara, Nataliya Milman, Beverley Shea, Gunnar Tómasson, Peter Tugwell, \\ Haner Direskeneli, and Peter A. Merkel
}

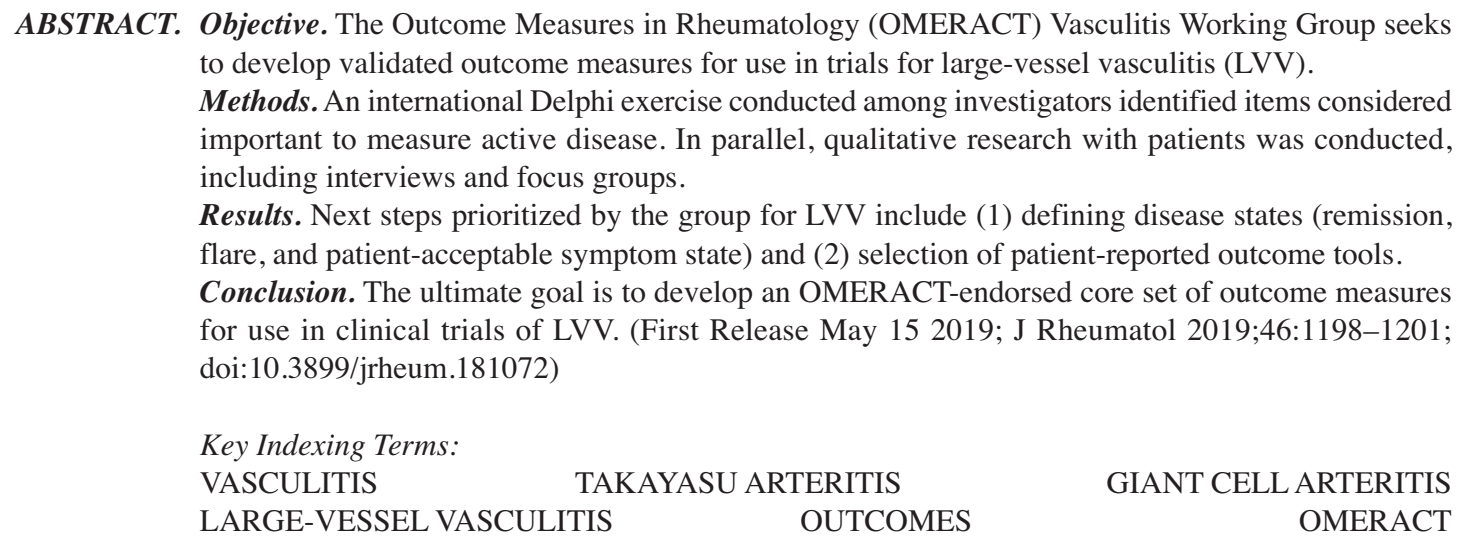

From the Division of Rheumatology, University of Ottawa, Ottawa Hospital Research Institute; Division of Rheumatology, Department of Medicine, and School of Epidemiology and Public Health, Faculty of Medicine, University of Ottawa; Department of Clinical Epidemiology, Ottawa Hospital Research Institute, Ottawa, Ontario, Canada; University of the West of England; University of Bristol; University Hospitals Bristol National Health Service (NHS) Trust, Bristol; Leeds Institute of Rheumatic and Musculoskeletal Medicine; Leeds Teaching Hospitals NHS Trust, Leeds, UK; Division of Rheumatology and Department of Biostatistics, Epidemiology, and Informatics, University of Pennsylvania, Philadelphia, Pennsylvania; Division of Rheumatology, University of California at Los Angeles, Los Angeles, California; Division of Rheumatology and Immunology, The Ohio State University Wexner Medical Center, Columbus, Ohio, USA; Discipline of Medicine, University of Adelaide; The Queen Elizabeth Hospital, Adelaide, Australia; Fatih Sultan Mehmet Training and Research Hospital; Division of Rheumatology, Department of Internal Medicine, Istanbul University, Istanbul Faculty of Medicine; Division of Rheumatology, Department of Internal Medicine, Istanbul University-Cerrahpasa, School of Medicine, Istanbul; Division of Rheumatology, Marmara University, School of Medicine, Marmara, Turkey; Department of Internal Medicine, University Paris Diderot, Paris, France; Department of Public Health Sciences, University of Iceland, Reykjavik, Iceland.

This work was funded in part by the US Vasculitis Clinical Research Consortium (VCRC). The VCRC is part of the Rare Diseases Clinical Research Network, an initiative of the Office of Rare Diseases Research, National Center for Advancing Translational Science (NCATS). The VCRC is funded through collaboration between NCATS, and the National Institute of Arthritis and Musculoskeletal and Skin Diseases (U54 AR057319), and has received funding from the National Center for Research Resources (U54 RR019497).

S.Z. Aydin, Associate Professor in Rheumatology, Division of Rheumatology, University of Ottawa, Ottawa Hospital Research Institute; J.C. Robson, MRCP, PhD, Consultant Senior Lecturer, University of the West of England, and Honorary Senior Lecturer, University of Bristol, and Honorary Consultant in Rheumatology, University Hospitals Bristol NHS Trust; A.G. Sreih, MD, Assistant Professor of Medicine, Division of Rheumatology, University of Pennsylvania; C. Hill, MD, Professor,
Discipline of Medicine, University of Adelaide, and Consultant Rheumatologist, The Queen Elizabeth Hospital; F. Alibaz-Oner, MD, Associate Professor of Rheumatology, Fatih Sultan Mehmet Training and Research Hospital; S. Mackie, MRCP, PhD, Associate Professor, Leeds Institute of Rheumatic and Musculoskeletal Medicine, and Honorary Consultant Rheumatologist, Leeds Teaching Hospitals NHS Trust; S. Beard, Bmus, Adelaide, Australia; A. Gul, MD, Professor of Rheumatology, Division of Rheumatology, Department of Internal Medicine, Istanbul University, Istanbul Faculty of Medicine; G. Hatemi, $M D$, Professor of Medicine, Division of Rheumatology, Department of Internal Medicine, Istanbul University-Cerrahpasa, School of Medicine; T.A. Kermani, MD, MS, Associate Professor of Medicine, Division of Rheumatology, University of California at Los Angeles; A. Mahr, MD, PhD, Professor of Internal Medicine, Department of Internal Medicine, University Paris Diderot; A. Meara, MD, Assistant Professor, Division of Rheumatology and Immunology, The Ohio State University Wexner Medical Center; N. Milman, MD, Assistant Professor, Division of Rheumatology, University of Ottawa, and Division of Rheumatology, The Ottawa Hospital, and Department of Clinical Epidemiology, Ottawa Hospital Research Institute; $B$. Shea, PhD, Clinical Investigator and Adjunct Professor, Ottawa Hospital Research Institute, and School of Epidemiology and Public Health, Faculty of Medicine, University of Ottawa; G. Tómasson, MD, PhD, Assistant Professor of Medicine, Department of Public Health Sciences, University of Iceland; P. Tugwell, MD, Professor, Division of Rheumatology, Department of Medicine, and School of Epidemiology and Public Health, Faculty of Medicine, University of Ottawa, and Clinical Epidemiology Program, Ottawa Hospital Research Institute; H. Direskeneli, MD, Professor of Medicine, Division of Rheumatology, Marmara University, School of Medicine; P.A. Merkel, MD, MPH, Professor of Medicine and Epidemiology, Division of Rheumatology and Department of Biostatistics, Epidemiology, and Informatics, University of Pennsylvania.

Address correspondence to Dr. P.A. Merkel, Chief, Division of Rheumatology, Professor of Medicine and Epidemiology, University of Pennsylvania, White Building, 5th Floor, 3400 Spruce St., Philadelphia, Pennsylvania19104,USA.E-mail: pmerkel@upenn.edu

Accepted for publication February 20, 2019. 
Large-vessel vasculitis (LVV) is a rare set of diseases that mainly affect the aorta and its primary branches ${ }^{1,2}$. The most common of the diseases are giant cell arteritis (GCA) and Takayasu arteritis (TA). Mainly because of the rarity of these diseases, there is no standardized protocol on how to monitor patients, when to repeat arterial imaging, or when to change therapy. This situation leads to significant variations in clinical practice.

In the last 5 years, the Outcome Measures in Rheumatology (OMERACT) Vasculitis Working Group has been developing a core set of domains in LVV. The working group recognizes the need to obtain final endorsement of the domains prior to selecting and/or developing associated outcome measurement instruments. Concurrently, the group has been conducting parallel projects to understand the perspectives of experienced physicians, investigators, and patients regarding outcomes of importance in $\mathrm{LVV}^{3,4}$. The following work has been completed: a comprehensive literature review to assess the knowledge gap in this area ${ }^{3}$, an international Delphi exercise among clinicians and investigators to identify items considered important to determine active disease status in $\mathrm{LVV}^{5}$, and qualitative research with patients with $\mathrm{LVV}^{6}$. A draft set of core domains for LVV was proposed ${ }^{4}$. The group is currently working on 2 additional projects in LVV: (1) defining disease states [remission, flare, and Patient Acceptable Symptom State (PASS)] and (2) developing patient-reported outcome tools.

The projects outlined below are being pursued in line with OMERACT processes ${ }^{7,8}$, and were presented at the OMERACT 2018 meeting at which feedback was obtained from meeting participants.

\section{Defining Disease Status in Large-vessel Vasculitis}

A simple definition of "active disease" in TA was proposed by Kerr, et al based on the presence of constitutional symptoms, new bruits, acute-phase reactants, or new angiographic features of arteritis ${ }^{1}$. There are 2 other composite indices that were specifically developed for TA, DEI.Tak (Disease Extent Index-Takayasu) and ITAS2010 (The Indian Takayasu's Arteritis Score 2010) $)^{9,10}$, and proposed to help define disease states. DEI.Tak was based on the Birmingham Vasculitis Activity Score (BVAS) using the same 11 organ systems, some of which are not frequently affected in LVV; some weighting was applied to increase the effect of cardiovascular items. However, DEI.Tak was shown to have significant discrepancies with physicians' judgments of activity ${ }^{11}$. ITAS2010, a modification of DEI.Tak, has only 6 systems and is weighted even more heavily toward vascular items 9 . This modification modestly increased the agreement with physicians' assessments, but still leaves substantial discrepancies between the 2 assessments ${ }^{12}$. In GCA, only 1 study investigated BVAS in a prospective observational cohort of patients with GCA; it showed that most categories of the BVAS were not applicable in GCA, whereas many compo- nents of active disease were identified in the "other" category, not contributing to the total BVAS ${ }^{13}$.

The randomized controlled trials involving TA and GCA conducted to date usually defined relapse and remission based on the presence/absence of signs and symptoms and/or acute-phase reactants (Table 1). These definitions were not obtained by a data-driven approach or using patients' perspectives, but through expert opinion.

The disease states in LVV outlined above have not been well-defined, and definitions are not uniform across studies. The complexity of the disease makes it difficult to differentiate "activity" from "damage" to define remission or relapse. Further, disease states have not been studied from the patients' perspective. PASS, the value beyond which patients can consider themselves well, has not been studied in LVV. PASS is independent of treatment decisions and purely reflects patients' perspectives, and therefore could be a useful tool to understand patients' perceptions of clinically meaningful disease states ${ }^{14}$.

The aim of our project is also to create a definition of disease states in LVV for use in clinical trials. To arrive at widely acceptable and feasible definitions, data elements will be preferentially used if they are considered important by physicians and patients, routinely identified in standard clinical practice, specific to disease activity (not damage), and not redundant with each other. The following steps will be carried out to achieve this goal: (1) a patient survey will be designed and implemented to receive patient input on items from the physician Delphi and new items considered relevant to disease states; (2) the features prioritized by patients, along with the results from the physician Delphi, will be reviewed during a meeting of key investigators and patients with the aim of reaching consensus on item reduction and selection for use; and (3) data will be collected from patients with LVV and their physicians within a multicenter longitudinal cohort, including the effect of each of the items on physicians' judgments of remission, relapse, and change in therapy. Patients' input on remission, flare, and PASS will also be collected and analyzed. These steps were discussed in the OMERACT meeting, with encouraging feedback from attendees including emphasizing that collecting data to develop a definition of different diseases will require significant input from the patients.

\section{Patient-reported Outcomes in LVV}

The OMERACT Vasculitis Working Group has highlighted the development of a disease-specific patient-reported outcome (PRO) measure for TA and GCA as one of the next steps in its research agenda ${ }^{4,15}$. In TA and GCA, commonly used generic tools such as the 36-item Medical Outcomes Study Short Form-36 questionnaire (SF-36) do not distinguish between clinically important groups such as patients with and without visual loss or systemic symptoms ${ }^{16,17,18,19}$.

Personal non-commercial use only. The Journal of Rheumatology Copyright (C) 2019. All rights reserved. 
An international collaboration has therefore been formed to develop disease-specific PRO measures.

As a first step in TA, 12 patients from the United States participated in semistructured, individual, in-person interviews and a total of 19 patients in Turkey participated in 2 focus groups ${ }^{6}$. The interviews and group sessions were recorded, transcribed, and analyzed with NVivo. A line-by-line review of narrative data was used to develop themes describing the effect of TA on patients' life. US patients were invited to free-list terms that they associated with disease states (active disease and remission). The Smith Salience Index was used to identify the most salient terms. Pain, fatigue, and emotional impact emerged as common themes. The most salient terms were pain/discomfort and fatigue/low energy levels during active disease, and pain/discomfort and emotional impact during remission. Outcomes were similar between the 2 countries. Current efforts are focusing on creating a disease-specific PRO tool for TA based on the results of the qualitative studies.

For GCA, the results of the first stage (qualitative interviews with 36 patients in the United Kingdom and Australia) were presented at the LVV Special Interest Group (SIG) session at OMERACT 2018. All patients had a confirmed diagnosis of GCA on temporal artery biopsy or ultrasound. Patients were purposely sampled to include a range of ages, sex, disease duration, and disease manifestations (specifically visual loss and large-vessel involvement). Initial overarching themes that emerged included "anxieties around getting a diagnosis of GCA," "description of symptoms related to GCA and its treatment" (including visual disturbance), "lack of bodily strength, stability, and stamina; difficulties with completing daily tasks," "difficulties with participating in social activities, work, and caring roles," "not feeling normal and impact on general perception of health," and "anxiety and fear of the future" 20 . Key contextual factors around how patients experience GCA were also discussed, including the development of adverse effects and comorbidities, receiving support from family and friends, and self-management techniques such as maintaining physical activity. Discussions at OMERACT 2018 included the potential to expand the qualitative work into another geographic area by patients with GCA in Turkey, to ensure that the full range of themes of importance to patients is identified.

Themes are also being developed further into candidate questionnaire items for a disease-specific GCA PRO. Among the knowledge gained from the OMERACT conference was the importance of having questions that differentiate between patients in states of active disease and remission. In addition, identifying any background effect on health-related quality of life (e.g., symptoms related to glucocorticoid-related adverse effects or physical deconditioning because of the disease or treatment) was highlighted within the SIG. It was also decided to incorporate further prompts into the cognitive interview stage for the GCA PRO to ask patients to describe the start of their disease, flares, and periods of remission. This qualitative work will be carried out as part of the cognitive interview stages in the United Kingdom and Australia and will be incorporated into the initial qualitative work planned in Turkey. The focus on flare will inform the development of the GCA PRO but could also be used to help define appropriate questions for the disease states patient survey planned (as outlined above)

\section{Summary and Research Agenda}

The OMERACT Vasculitis Working Group has suggested a preliminary core set of domains for $\mathrm{LVV}^{4}$, and has a new research agenda for the next 2 years:

- Achieve full endorsement of a core set of domains for LVV.

- Select and/or develop validated instruments for each domain in LVV.

- Advance PRO research in LVV by gathering more patient-derived data on disease-related quality of life issues, including regarding different treatment regimens, with an ultimate goal of developing an LVV-specific PRO instruments.

- Define disease states for use in clinical trials of LVV through data-driven methods that include input of all stakeholders.

- Work toward an endorsed core set of outcomes for LVV that include domains with matching validated outcome measures.

\section{REFERENCES}

1. Kerr GS, Hallahan CW, Giordano J, Leavitt RY, Fauci AS, Rottem M, et al. Takayasu arteritis. Ann Intern Med 1994;120:919-29.

2. Seo P, Stone JH. Large-vessel vasculitis. Arthritis Rheum 2004;51:128-39.

3. Direskeneli H, Aydin SZ, Kermani TA, Matteson EL, Boers M, Herlyn K, et al. Development of outcome measures for large-vessel vasculitis for use in clinical trials: opportunities, challenges, and research agenda. J Rheumatol 2011;38:1471-9.

4. Sreih AG, Alibaz-Oner F, Kermani TA, Aydin SZ, Cronholm PF, Davis T, et al. Development of a core set of outcome measures for large-vessel vasculitis: report from OMERACT 2016. J Rheumatol 2017;44:1933-7.

5. Aydin SZ, Direskeneli H, Merkel PA; International Delphi on Disease Activity Assessment in Large-vessel Vasculitis. Assessment of disease activity in large-vessel vasculitis: results of an international Delphi exercise. J Rheumatol 2017;44:1928-32

6. Sreih AG, Alibaz-Oner F, Easley E, Davis T, Mumcu G, Milman N, et al. Health-related outcomes of importance to patients with Takayasu's arteritis. Clin Exp Rheumatol 2018;36 Suppl 111:51-7.

7. Boers M, Kirwan JR, Wells G, Beaton D, Gossec L, d'Agostino MA, et al. Developing core outcome measurement sets for clinical trials: OMERACT filter 2.0. J Clin Epidemiol 2014;67:745-53.

8. Boers M, Kirwan JR, Tugwell P, Beaton D, Bingham CO III, Conaghan PG, et al. The OMERACT Handbook. [Internet. Accessed April 3, 2019.] Available from: https://omeract.org/resources

9. Misra R, Danda D, Rajappa SM, Ghosh A, Gupta R, Mahendranath $\mathrm{KM}$, et al; Indian Rheumatology Vasculitis (IRAVAS) group. Development and initial validation of the Indian Takayasu Clinical

Personal non-commercial use only. The Journal of Rheumatology Copyright $\odot$ 2019. All rights reserved. 
Activity Score (ITAS2010). Rheumatology 2013;52:1795-801.

10. Sivakumar MR, Bacon PA. The Indian perspective of Takayasu arteritis and development of a disease extent index (DEI.Tak) to assess Takayasu arteritis. Rheumatology 2005;44 Suppl 3:iii6-7.

11. Aydin SZ, Yilmaz N, Akar S, Aksu K, Kamali S, Yucel E, et al. Assessment of disease activity and progression in Takayasu's arteritis with Disease Extent Index-Takayasu. Rheumatology 2010;49:1889-93.

12. Alibaz-Oner F, Aydin SZ, Akar S, Aksu K, Kamali S, Yucel E, et al. Assessment of patients with Takayasu arteritis in routine practice with Indian Takayasu Clinical Activity Score. J Rheumatol 2015;42:1443-7.

13. Kermani TA, Cuthbertson D, Carette S, Hoffman GS, Khalidi NA, Koening CL, et al; Vasculitis Clinical Research Consortium. The Birmingham Vasculitis Activity Score as a measure of disease activity in patients with giant cell arteritis. J Rheumatol 2016;43:1078-84.

14. Tubach F, Ravaud P, Baron G, Falissard B, Logeart I, Bellamy N, et al. Evaluation of clinically relevant states in patient reported outcomes in knee and hip osteoarthritis: the patient acceptable symptom state. Ann Rheum Dis 2005;64:34-7.
15. Aydin SZ, Direskeneli H, Sreih A, Alibaz-Oner F, Gul A, Kamali S, et al. Update on outcome measure development for large vessel vasculitis: report from OMERACT 12. J Rheumatol 2015; 42:2465-9.

16. Jobard S, Magnant J, Blasco H, Ferreira-Maldent N, Griffoul I, Diot E, et al. Quality of life of patients treated for giant cell arteritis: a case-control study. Clin Rheumatol 2017;36:2055-62.

17. Akar S, Can G, Binicier O, Aksu K, Akinci B, Solmaz D, et al. Quality of life in patients with Takayasu's arteritis is impaired and comparable with rheumatoid arthritis and ankylosing spondylitis patients. Clin Rheumatol 2008;27:859-65.

18. Yilmaz N, Can M, Oner FA, Kalfa M, Emmungil H, Karadag O, et al. Impaired quality of life, disability and mental health in Takayasu's arteritis. Rheumatology 2013;52:1898-904.

19. Alibaz-Oner F, Sreih AG, Merkel PA, Direskeneli H. Patient-reported outcomes in Takayasu's arteritis. Presse Med 2017;46:e225-e7.

20. Robson J, Almeida C, Dawson J, Bromhead A, Mackie SL, Hill CL, et al. A multinational qualitative study in giant cell arteritis: patient perceptions of diagnosis, treatment, impact on health-related quality of life and contextual factors [abstract]. Ann Rheum Dis 2018;17:777. 